\title{
Changing dynamics and travel evading: a case of Indian tourists amidst the COVID 19 pandemic
}

\author{
Vikas Gupta, Ignatius Cahyanto, Manohar Sajnani and Chetan Shah
}

\author{
Vikas Gupta is based at \\ Amity School of Hospitality, \\ Amity University, Noida, \\ India. Ignatius Cahyanto is \\ based at the Department of \\ Hospitality Management, \\ University of Louisiana at \\ Lafayette, Lafayette, \\ Louisiana, USA. \\ Manohar Sajnani is based \\ at Amity Institute of Travel \\ and Tourism, Amity \\ University, Noida, India. \\ Chetan Shah is based at \\ the Department of Tourism \\ and Hospitality \\ Management, The \\ University of the South \\ Pacific, Suva, Fiji.
}

\begin{abstract}
Purpose - This study aims to analyse the factors that caused Indian tourists to avoid travelling abroad because of the recent outbreak of COVID-19 in 2020. It will also identify the relationship between the perceived risk of travelling and the probability of travel evading in India owing to COVID-19.
\end{abstract}

Design/methodology/approach - This study used an online structured questionnaire to collect data from Indian tourists to study six independent variables linked with their behavioural intentions (travel evading). The health belief model was used to examine tourist behaviour.

Findings - The results revealed a positive correlation between the perceived risk associated with COVID-19 and travel avoidance. Familiarity with COVID-19 was positively correlated with travel evading behaviours.

Practical implications - This study will assist stakeholders from around the world to adequately identify and thoroughly plan for logistical problems associated with travel such as travel insurance and pre-travel booking expenses to reduce travel evading behaviour and promote travel.

Originality/value - While a few studies have been conducted related to pandemics (Ebola, MERS-CoV, $S A R S$ ), there is a paucity of literature that examines the factors which influence tourists' travel evading behaviour owing to COVID-19. Moreover, most of the previous literature on pandemics is concentrated on American and European countries, whereas studies on the Indian sub-continent are very scarce. This study will fill this gap and will identify the factors which influence tourists in India to evade travel in response to COVID-19.

Keywords India, Pandemic, COVID-19, Novel coronavirus, Health belief model, Travel behaviours

Paper type Research paper

\section{Introduction}

Received 20 April 2020 Revised 2 August 2020 5 October 2020

Accepted 14 December 2020

C Vikas Gupta, Ignatius Cahyanto, Manohar Sajnani and

Chetan Shah. Published in Journal of Tourism Futures. Published by Emerald Publishing Limited. This article is published under the Creative Commons Attribution (CC BY 4.0) license. Anyone may reproduce, distribute, translate and create derivative works of this article (for both

commercial and non-commercial purposes), subject to full attribution to the original publication and authors. The full terms of this license may be seen at http:// creativecommons.org/licences/by/ 4.0/legalcode
Recently, the global tourism and hospitality sectors have been adversely affected by two significant drivers: health emergencies and climatic changes (Kuo et al., 2008). Earlier global pandemics such as SARS, MERS-CoV, Ebola, Avian Flu and H1N1 influenza virus caused much greater damage to the global tourism and travel industry as compared to the more localised natural disasters and crises such as 9/11, Hurricane Katrina, etc., resulting in huge job losses, severe financial losses and shutdowns and human casualties (Page et al., 2006). Previous studies (Cahyanto et al., 2016; Lee et al., 2012; Kuo et al., 2008) have consistently found that global pandemics have significantly contributed to higher levels of concern by travellers about risks associated with travel (both domestic and international). The global tourism and hospitality industry had earlier succumbed to various pandemic disease outbreaks such as Middle-Eastern Respiratory Syndrome (MERS-CoV) in 2012, Severe Acute Respiratory Syndrome (SARS) during 2002-2004, Ebola in 2014, Avian flu/ H1N5 in 2005 and Swine Flu/H1N1 in 2009 causing huge financial and human losses (Leggat et al., 2010). 
One of the most recent and devastating global health emergencies is the outbreak of novel coronavirus (COVID-19) which is expected to cause unprecedented damage to the international economy. The tourism and hospitality industry are especially vulnerable to this pandemic. A decline of $20 \%$ to $30 \%$ in the international tourist arrivals and a loss of US $\$ 300$ bn-US\$450bn in international tourism receipts is anticipated as a result of COVID-19 (UNWTO, 2020). Previous literature suggests that responses to a pandemic outbreak usually result in travel-related concerns (Lee et al., 2012) and disease perceptions that alter travel patterns (Mavondo and Reisinger, 2005). This might be due to travellers' adaptive behaviours that are used to reduce their chances of contracting the disease.

Globally, tourists' perceptions regarding COVID-19 are largely negative. A survey conducted by The Economic times (2020) in India revealed that more than three-fourths of Indians are concerned about COVID-19, but around two-thirds have full confidence in the Central Government's capability to deal with the pandemic. A survey conducted by Statista (2020) found that the travel restrictions and countrywide lockdown by the Central Government in India will have a significant negative impact on all forms of domestic and international tourism in India, especially on the hospitality and service sectors. However, these surveys did not consider the primary reason for such travel behaviours, nor did they elucidate on whether travellers are concerned about the pandemic outbreak, both of which are vital for travel cognisance.

While the association between the pandemic and travel has been widely discussed in previous studies (Leggat et al., 2010; Kuo et al., 2008), the literature on probable tourist behaviours during a pandemic is still very scarce. Due to the devastating impact of COVID19 on the Indian tourism and hospitality industry and several COVID-19 cases in the country, knowledge regarding tourist behaviour warrants further investigation as this situation might lead to travel evading and avoidance. Similarly, studies on tourists' beliefs, perceptions and attitudes regarding the prevention and transmission of COVID-19 are very limited. Due to the rapid transmission of COVID-19 in India and the subsequent negative publicity in the international media, there is a possibility that the tourists' travel behaviours might be affected due to this (Hindustan Times, 2020). Thus, the authors were concerned about the degree to which these tourist perceptions might influence their travel-related behaviours. Furthermore, to date, studies on the association between travel intentions and COVID-19 pandemic are nascent, and the situation remains fluid. While there are several recent studies addressing COVID-19 and travel, this paper seeks to explain the reasons for travel behaviour, which to date is under studied.

Understanding tourists' behaviour and its linkage with their risk perceptions is important due to the ever changing landscape of the COVID-19 (Yang and Chen, 2020) and is necessary to gain active control over the pandemic outbreak (Lee et al., 2012). This study applied the health belief model (HBM) to investigate how tourist behaviours are influenced by cognitive factors during the COVID-19 pandemic outbreak in India as it proposes that engaging in defensive behaviour may be affected by perceived risks and benefits. In previous studies, this model was used to study people's outlook towards vaccinations (Brewer and Hallman, 2006) and tourist's perceptions of risk and their risk-related behaviour (Cahyanto et al., 2016; Huang et al., 2020). For this study, we investigated the factors responsible for tourists' travel evading behaviour during the COVID-19 pandemic. Explicitly, the research questions developed for this study were:

$R Q 1$. Is there any significant relationship between the probability of travel evading and perceived risk of travel due to COVID-19 in India?

$R Q 2$. Is there any significant relationship between the probability of travel evading and perceived severity due to COVID-19 in India?

RQ3. Is there any significant relationship between the probability of travel evading and personal-efficacy due to COVID-19 in India? 
$R Q 4$. Is there any significant relationship between the probability of travel evading and perceived vulnerability due to COVID-19 in India?

$R Q 5$. Is there any significant relationship between the probability of travel evading and subjective acquaintance due to COVID-19 in India?

RQ6. Is there any significant relationship between the probability of travel evading and the designated socio-demographic factors due to COVID-19 in India?

A conceptual model framework showing the study objectives and the relationship between the constructs and the behavioural intentions (travel evading) of tourist is provided in Figure 1.

\section{Literature review}

\section{Novel coronavirus (COVID-19) and its emergence}

Chinese health officials in late December 2019 examined a group of non-conforming pneumonia cases in recent visitors to a wet or seafood market in the city of Wuhan, Hubei province of China, who presented with a cough, fever and respiratory distress (Zhu et al., 2019). Further investigation revealed the virus to be distinct from the earlier SARS-CoV and MERS-CoV, and the new variant was named SARS-Cov-2 (Lu et al., 2020) by the International Committee on Taxonomy of viruses (Gorbalenya et al., 2020) and the illness caused by this virus was dubbed Corona virus disease-2019 (COVID-19) by World Health Organisation (WHO).

As per the latest statistical report (as of 2 October, 2020) by Worldometers (2020) regarding COVID-19, there are 34,470,778 confirmed cases with more than 1,027,489 deaths globally in 206 countries and two international conveyances. To date, COVID-19 is considered to be a less severe disease as compared to MERS-CoV and SARS with mortality rates of around $3 \%-4 \%$ as compared to $35 \%$ for MERS-CoV and $10 \%$ for SARS (Hui et al., 2020). However, recent trends are concerning and extremely alarming. A majority of the cases as per the

\section{Figure 1 Conceptual model framework of the study}

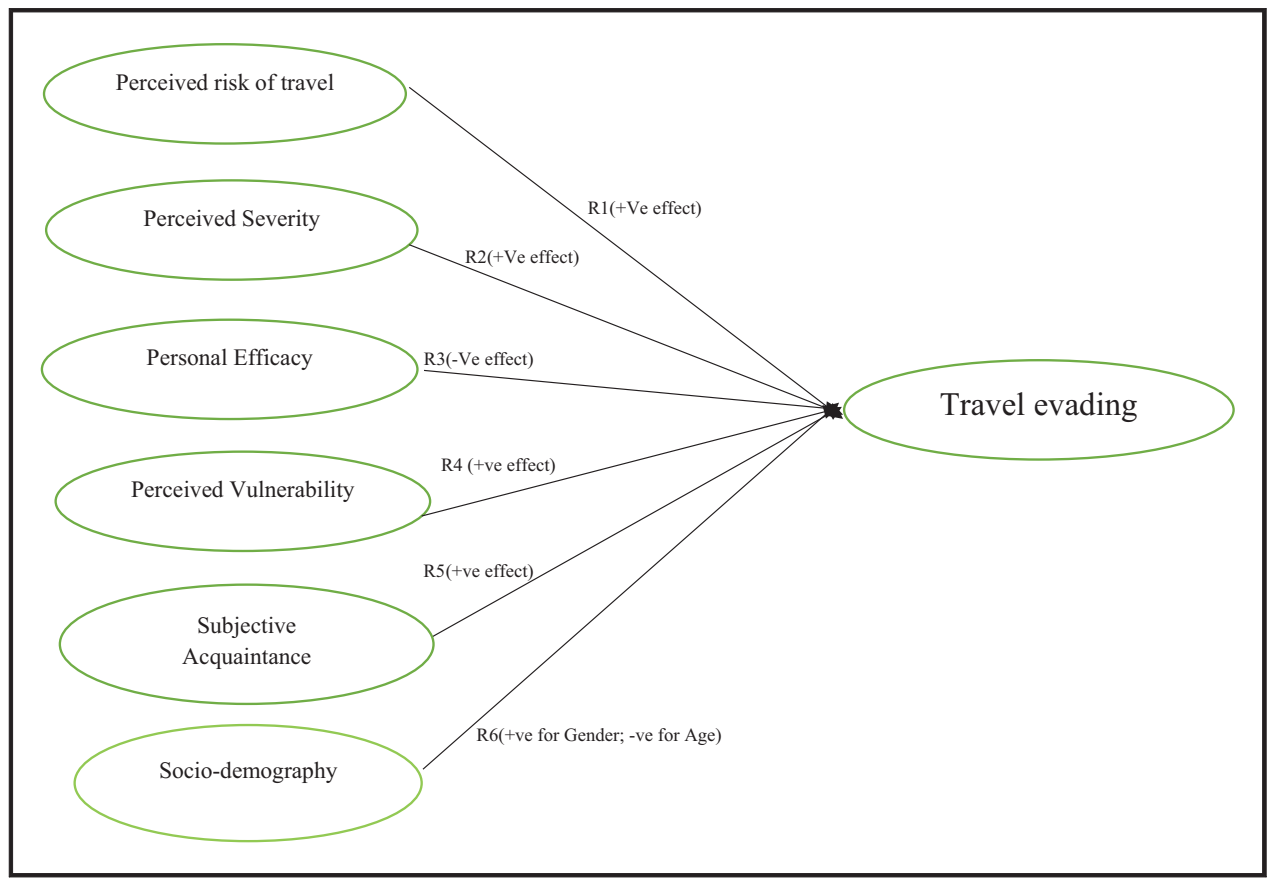


latest trends (Worldometers, 2020) were found to be increasing rapidly in the USA (21.74\%), India (18.54\%), Brazil (14.06\%), Russia (3.43\%) and subsequently decreasing in China $(0.24 \%)$. The Chinese Government's actions to curtail the virus included strict travel restrictions, timely limiting and stoppage of flight operations, a complete ban on social gatherings and keeping the suspected cases in quarantine or self-isolation for two weeks (Buckley, 2020; Yuda and Tani, 2020). However, the case was not the same for the US and European countries. Transmission remained unnoticed in these countries for a considerable period due to initial lenient governmental approaches with regards to travellers from the outside countries, failure to adequately perform medical tests for detecting COVID-19 and considerable delay in restricting of travel movement (Aksoy, 2020; Bergmann, 2020; Maxouris, 2020). By the time it was realised, numerous transmission chains had developed due to community transmission, which exponentially increased the number of cases in these countries (Godin, 2020). From this perspective, it is already clear that tourism and hospitality will be among the most mal-affected industries with this global pandemic with major players such as Airbnb, Uber, all major airlines and hotels already showing sharp declines in their sales and revenue (Baker, 2020; Riley, 2020).

To control viral transmission further, WHO, (2020) recommended prevention guidelines (frequent hand washing and use of alcohol hand sanitisers; covering mouth and nose; physical distancing; self-isolation if symptomatic; not touching mouth, nose or eyes with unclean hands). In India, tourist movement was restricted by the Central Government's travel and visa restrictions (Bureau of Immigration, 2020) where travel bans were imposed on the movement of people from outside of India from 18 March, 2020 for a period of three weeks and the announcement of a complete lockdown in the country.

\section{Study variables and the health belief model}

This study applied the use of constructs/variables obtained through the HBM to measure participants' travel-related perceptions regarding COVID-19. The model had been earlier tested to explore the constructs associated with risk associated behaviours (Nicholls, 2006; Rosenstock et al., 1988). Chapman and Coups (1999) found that if the people sense that they are vulnerable towards a disease/illness and perceive it to be severe and have a belief that their precautionary behaviours will compensate the contraction cost, then they are more likely to engage in risk reduction behaviours. HBM has also been regarded an effective medium for endorsing health education and engaging measures to correct people's maladaptive behavioural responses (Sharifirad et al., 2009). The chief constructs of the HBM are perceived vulnerability, perceived risk, perceived benefits, personal efficacy, perceived severity and action cues (Carpenter, 2010). The constructs such as subjective acquaintance related to COVID-19, perceived risk of travelling and the respondent's sociodemographic factors were included into the model to explain the reasons of traveller's travel evading perceptions in India (Lepp and Gibson, 2003).

Perceived risks and benefits concerning travel intentions were found to have the sturdiest extrapolative influences while measuring the HBM constructs (Carpenter, 2010). The risks perceived and safety perceptions regarding a destination greatly influence travel behaviours (Crompton, 1992). When there is a potential risk attached with travelling to a particular destination, travellers may change their travel destination, alter their travel behaviour or obtain supplementary information prior to travel (Carr, 2001; Englander, 1991). However, perceived severity had the weakest influence on travellers' behavioural selections (Janz and Becker, 1984). Various factors which were found to have a moderating effect on the extrapolative influence of the HBM were found to be: time duration while gauging travellers' behaviour and beliefs; actions related to prevention and treatment; and routines linked with various behaviours (Brewer and Fazekas, 2007). It was also discovered that if the people believe that the adaption benefit of a behaviour is high and they are prone or 
vulnerable to a specific illness, then they will be more tolerant of the precautionary measures (Carpenter, 2010).

Perceived risks refer to whether a potential traveller feels comfortable and safe during a trip, and it is one of the stoutest predictors of travel safety (Gupta and Sajnani, 2019). Travellers who perceive higher risks are less inclined towards travel (Sharifirad et al., 2009). Travellers may perform a price-benefit evaluation and weigh perceived risks against benefits before making a travel decision (Hanson and Benedict, 2002). Those who perceive more risks over benefits are less likely to perform a travel-specific behaviour (Sharifirad et al., 2009). Considering this study, the perceived risk of contracting COVID-19 may hamper the participants' likelihood of performing the intended travel behaviour. Therefore, the destination stakeholders should use a robust strategy to reduce the perceived risks amongst the travellers.

Perceived benefits are related to reducing one's vulnerability towards an illness (i.e. COVID19) through specific behaviours. People who perceive greater benefits from using a behaviour are more likely to perform them (Adams and Scott, 2000). For example, to administer a vaccine on a set population, the promotion of linked benefits is essential. Those who perceive limited or no benefits might not engage in such programmed behaviour (Sharifirad et al., 2009). Thus, for any vaccination program to be successful, it needs to take the importance of perceived benefits into account. However, in some cases, perceived benefits might not be enough to lure the entities to engage in specific behaviours. In a study conducted by Cahyanto et al. (2016) on multiple sclerosis patients, the perceived benefits of physical exercise were found to be insufficient to cause the patients to engage in exercise. Personal-efficacy was found to be a more adequate and positive forecaster of exercise with these patients than the perceived benefits. Thus, there is minimal or no effect of perceived benefits on individual behaviour.

Personal-efficacy is a person's confidence in their ability to perform healthy behaviours and refers to the ability to control one's behaviour and motivation (Bandura, 1977). Travellers with higher levels of personal efficacy have a greater probability of following through on intended behaviour during aversive circumstances like the COVID-19 pandemic. Possessing high perceived personal-efficacy may help individuals to adjust to preventive behaviours, which furthermore may assist them to avert drastic outcomes during pandemics (Rosenstock et al., 1988). Therefore, the perceptions of personal-efficacy should be considered while aiming to increase the use of healthy preventive measures amongst individuals.

Perceived vulnerability was found to be an important construct in the HBM. It posits that individuals who perceive higher levels of vulnerability to be associated with a specific illness are more likely to engage in behaviours to reduce their risk of contracting that illness (Hanson and Benedict, 2002). It can also be defined as the belief of an individual that they will develop the symptoms of an illness (Brewer and Fazekas, 2007). In a cross-sectional study, De Coninck et al., 2020, found that higher perceived vulnerability correlates with a greater likelihood to take appropriate preventive measures to avoid contracting COVID-19.

Perceived severity refers to a person's belief regarding the seriousness of contracting a disease. An individual's perceived severity can vary considerably and usually involves the evaluation of social (i.e. relationships, family) and medical outcomes (i.e. disability or death). The degree of an individual's perceived severity is found to be directly proportional to the engagement in preventive and protective measures (Hanson and Benedict, 2002), except in a few studies evaluating the severity of HIV contraction due to non-usage of condoms during sexual interaction (Hounton et al., 2005). Thus, the more an individual perceives a disease to be severe, the greater the probability that he or she will take precautionary actions. In a study of 937 South Korean subjects, Lee and You (2020) found that perceived severity was associated with a much higher propensity to engage in precautionary behaviours to avoid COVID-19. 
Cues to actions is the impetus required to accept a suggested health act by activating the individual's decision. These cues or signals can be external (newspaper, family illness history, advice from doctor or family member, etc.) or internal (cough, fever, vomiting, etc. depending on the symptoms). These are actually inner sources of motivation which endorses acceptance of a particular behaviour, such as taking precautionary measures such as engaging in physical distancing and avoiding crowds during COVID-19. In another cross-sectional study of 680 participants in Kerala, India, cues to action was found to be significantly correlated with the adoption of measures to avoid COVID-19. A total of $80 \%$ of respondents reported that cues to action were instrumental in their decision to engage inappropriate health measures (Jose et al., 2020).

\section{Perceived risk of travelling and travel evading due to COVID-19}

Perceived risk related to travel and travellers' travel evading perceptions have long been explored in the previous literature (Roehl and Fesenmaier, 1992; Tsaur et al., 1997). Travel risk perceptions have been categorised under seven dimensions, i.e. financial, functional, social, physical, psychological, satisfaction and time risk (Schiffman and Kanuk, 1991) or under the vacation, destination and physical-equipment risks classification (Roehl and Fesenmaier, 1992). Maser and Weiermair (1998) provided a categorisation of risks which is more conducive to the perspective of our study, i.e. risks linked with illness/disease, natural disaster, hygiene issues, language barriers, local crimes and ambiguity of destination laws; which was further confirmed and broaden by Mitchell and Vassos (1997) into 43 travel linked risk dimensions. Previous studies have found that due to the safety and security risks at the travel destination, travellers often become anxious and decline in the tourism demand is the most probable outcome due to travel evading by the visitors. This was confirmed during the tsunami (Morrison, 2005), 9/11 incidence (Arana and Leon, 2008), SARS outbreak in Asia (Pine and McKercher, 2004), Ebola in west-Africa (Cahyanto et al., 2016) and most recently related to COVID-19 pandemic (Binnicker, 2020).

COVID-19 has resulted in travel evading around the globe and has greatly endangered the tourism and hospitality sectors, given its dependence on mobility ( et al., 2020). A majority of travellers have postponed or cancelled their travel plans due to the danger of contraction of COVID-19 in India. This study will explore the factors which have influenced travel evading intentions in India through the previously mentioned variables of HBM which will be highly useful for the stakeholders and destination marketing organisation (DMO's) to strategize to boost the tourism and hospitality industry by reducing the risks involved.

\section{Methodology \\ Participants and data collection}

Data for this study was obtained through an online survey of 1,419 Indian travellers (both domestic and international). Ethical clearances were taken by the principal author prior to data collection. Participation in this study was voluntary. Confidentiality and anonymity of the respondents (as mentioned in the survey form) was also adequately maintained. Respondents were asked whether they wanted to participate, and only those interested were redirected to the questionnaire submission link. To increase involvement, the Dillman online questionnaire approach (Dillman et al., 2009) was used and included the generation of reminder emails and texts to participants. All forms were expansively checked for data consistency and accuracy. Few survey forms $(N=39)$ were found to be incomplete or having inconsistencies, which were not considered appropriate for further analysis and were rejected. The data collection process took four weeks to acquire responses from the respondents. As this relied on self-reported information, it might inherit some intrinsic bias (most probably the common method variance $[\mathrm{CMV}]$ ). To reduce this bias, factors were revised to circumvent unaccustomed phrasings and to follow question sequence order for the model. Finally, Harman's Single factor test was 
performed to establish the influence of bias which showed positive results and confirmed the absence of any bias within the factor items.

A total of 529 completed and worthy questionnaires were obtained with a response rate of $37 \%$ and included $54 \%$ males and rest females (46\%), mostly in the age brackets of 31-45years (32.70\%) followed by 19-30years (22.87), 46-60 year $(20.79 \%)$, above 60 years $(16.27 \%)$ and rest below 18 years $(7.37 \%)$. Most of the respondents were married $(54.83 \%)$ and have education background as postgraduate $(46.33 \%)$ followed by graduates $(29.67 \%)$, doctorates and above $(14.18 \%)$ and rest having a high school degree (9.82\%). Household income of the participants was found to be evenly distributed with majority having an income between INR $2,50,001$ and $6,00,000(28.30 \%)$ followed by INR 6,00,001-9,00,000 (26.50\%), more than INR 12,00,000 (20.40\%), INR 9,00,001-12,00,000 (19.50\%) and rest below INR $2,50,000$ (5.29\%). Most of the respondents were found to have not travelled abroad $(67.29 \%)$ in the past year and travel reason for the majority who travelled was leisure and holidays (15.50\%). Almost, all the respondents were found to be aware of the COVID-19 pandemic (99.10\%). The socio-demographic profiles of the respondents are provided in Table 1.

\section{Table 1 Respondent's socio-demographic profiles}

Profile of respondents $(N=529)$

Frequency (\%)

Gender

Male

$286(54.06)$

Female

$243(45.94)$

Age

Below 18 years

$39(7.37)$

19-30

$31-45$

$46-60$

$121(22.87)$

$173(32.70)$

$110(20.79)$

$61 \&$ above

$86(16.27)$

Marital status

Single

$239(45.17)$

Married

$290(54.83)$

Education levels

High school

$52(9.82)$

Graduate

$157(29.67)$

Post graduate

$245(46.33)$

Doctorate and above

$75(14.18)$

Annual household income (In INR)

Below 2,50,000

28 (5.29)

$2,50,001$ to $6,00,000$

$150(28.30)$

$6,00,001$ to $9,00,000$

$140(26.50)$

$9,00,001$ to $12,00,000$

$103(19.50)$

Above 12,00,000

$108(20.40)$

International travel in past 12 months

Once

$117(22.12)$

Twice

$33(6.24)$

Three-four times

$14(2.65)$

More than four times

$09(1.70)$

Never travelled abroad

$356(67.29)$

Awareness regarding COVID-19

Aware

$524(99.05)$

Not aware

$5(0.95)$

Note: INR = Indian National Rupees 


\section{Operationalisation}

The study variables were constructed using previous studies (Cahyanto et al., 2016; Lee et al., 2012) on the earlier epidemics and adjustments were made to make it more relevant and precise. Six independent variables associated with the HBM (i.e. perceived risk of travel, perceived vulnerability, perceived severity, personal efficacy, subjective acquaintance and socio-demographic factors) were used to study the travel evading intentions of the Indian travellers due to COVID-19. Measurement of the variables, i.e. perceived risk of travel (six statements adopted from Lee et al., 2012), perceived vulnerability (four statements adopted from Sharifirad et al., 2009), perceived severity (four statements adopted from Bish and Michie, 2010), and personal efficacy (five statements adopted from Anagnostopoulos et al., 2013) were done using the five-point Likert scale. The extent of subjective acquaintance (from not knowledgeable to highly knowledgeable) regarding COVID-19 was measured by one statement. Travellers' socio-demographic factors were measured by asking respondents about their gender, age, level of education attainment, household income and international travel history in the past 12 months. The dependent variable, i.e. traveller's travel evading intentions was measured through two statements on their likelihood of travel behaviour in and outside India after the first two months of the COVID-19 outbreak. Traveller's viewpoints concerning their travel evading intentions after the COVID-19 pandemic were highlighted as autonomous and empirical.

To investigate the perception of risks linked with the transmission of COVID-19, constructs of the HBM were used. This study applied the use of composite scores for all the statements recorded for specific study variables, i.e. perceived risk of travel, perceived vulnerability, perceived severity, personal efficacy towards COVID-19 along with their means and standard deviations. Research questions were answered using the ordered response model (ORM) by revealing the relationships between the constructs. For measuring the study parameters, maximum likelihood estimation was used. Multi-phase data analysis, including descriptive and reliability tests and ORM was used to link the probability of travel evading with the independent variables.

\section{Results}

To check the internal consistency of data, this study applied Cronbach's $\alpha$ reliability measure. The Cronbach's $\alpha$ values were recorded for all the variables and measured between 0.93 and 0.79 , which was well above the required levels and represented scale uni-dimensionality. The Kaiser-Meyer-Olkin (degree of sampling adequacy) was 0.87, which was over the required brink of 0.60 . Bartlett's test of sphericity was performed and was found to be noteworthy, $\chi^{2}$ $(330)=1,184, p<0.001$ and well below 0.05 confirming the reliability, consistency and data adequacy. Composite scores for all the statements recorded for a specific variable mentioning their respective means and standard deviations are presented in Tables 2-5.

Results revealed a high-risk perception for most of the variable items of HBM. $78.8 \%$ of respondents answered that they would avoid domestic travel while $94.70 \%$ reported refraining from International travel due to the pandemic. A majority of respondents $($ mean $=4.12$; percentage $=89.40 \%)$ deemed COVID-19 as dangerous, infectious and a risk to human life. Although respondents considered any form of travelling very risky, most of them considered international travel much riskier than domestic travel due to COVID-19. Results also suggested that almost $67 \%$ of the respondents had not travelled abroad in the past 12 months. The average mean score for perceived risk of travel was found to be 3.91 , suggesting a high-risk perception linked with the contraction of COVID-19.

For perceived vulnerability, the overall mean values were high (3.95) suggesting high perceived vulnerability to COVID-19 amongst respondents. Mean scores for perceived severity (3.06) with regards to COVID-19 were found to be evenly distributed and neutral. However, it was interesting to note that respondents 45-60years and older showed high 
Domestic air travel should be avoided considering the prevailing COVID-19 outbreak in India International Air travel should be avoided considering the COVID-19 outbreak

$\begin{array}{ll}3.92 & 1.22 \\ 4.12 & 0.91 \\ 3.63 & 1.29 \\ 3.56 & 1.14 \\ 4.06 & 0.98 \\ 4.19 & 0.96\end{array}$

Domestic travel is just as dangerous as the International travel

People around me seem to refrain from domestic air travel right now because of COVID-19

People around me seem to refrain from international air travel right now because of COVID-19

COVID-19 is a very dangerous and infectious disease and a potential threat to human life

Notes: $N=529$; five-point Likert scale: $1=$ Strongly disagree and $5=$ Strongly agree

\section{Table 3}

Composite scores for perceived vulnerability towards COVID-19

Question statements

$\begin{array}{cc}\text { Standard } & \text { Cronbach's } \\ \text { Mean deviation }(S D) & \text { alpha }(\alpha)\end{array}$

Perceived vulnerability

It is very likely that I will be exposed to novel coronavirus if I travel in the next few weeks, but I will not get sick

It is likely that I will contract novel coronavirus if I travel in the next few weeks

It is likely that I will contract novel coronavirus if I travel in India by air in the next few weeks

Notes: $N=529$; five-point Likert scale: 1 = Strongly disagree and $5=$ Strongly agree

$4.19 \quad 1.02$

\section{Table 4 Composite scores for perceived severity towards COVID-19}

Question statements

Perceived severity

I think, if I get infected with novel coronavirus, I will surely die

I am afraid that I may die if I contract novel coronavirus

If I test positive for COVID-19, I could pass it to my family and friends who may die

I am at a greater risk of dying if I contract novel coronavirus because of my general health

Notes: $N=529$; five-point Likert scale: 1 = Strongly disagree and $5=$ Strongly agree
Standard

Mean

deviation (SD)

Cronbach's alpha $(\alpha)$

0.79

2.67

3.04

3.63

1.09

1.02

1.23

\section{Table 5}

I have a fair idea and knowledge regarding the measures to prevent COVID-19 transmission

Mean

deviation $(S D)$ alpha $(\alpha)$

I am aware about the activities that could prevent contracting novel coronavirus

I am able to clearly identify and distinguish the symptoms of COVID-19

I am confident that I am able to take requisite action to prevent contracting novel coronavirus

I know what to do if I suspect that I am exposed to COVID-19

$\begin{array}{ll}3.09 & 1.19 \\ 3.58 & 1.29 \\ 3.43 & 1.25 \\ 3.02 & 1.17 \\ 3.26 & 1.16\end{array}$

Notes: $N=529$; five-point Likert Scale: $1=$ Strongly disagree and $5=$ Strongly agree; subjective acquaintance on COVID-19: mean $=4.02, \mathrm{SD}=1.09$, scale: $1=$ Not knowledgeable to $5=$ Highly knowledgeable 
perceived severity due to their general health. It was also revealed that respondents perceived a high risk of transmitting the disease to their family and friends if contracted themselves.

Mean scores for personal efficacy were also found to be high (3.27), which revealed that respondents have a fair knowledge of COVID-19 and are were versed in preventive measures. This was also confirmed by the overall high mean scores for subjective acquaintance (4.02) related to COVID-19 by the respondents.

\section{Results of ordered response model}

This model applied maximum likelihood estimation for measuring the parameters. The higher probability of evading travel due to COVID-19 by travellers in India is indicated by the positive parameters, and the reverse influence is shown by the negative parameter in the model. A substantial enhancement from the base model was revealed at -2 Log likelihood with a convergence rate of 3,540.444 $\left(\chi^{2}=1,121.234, \mathrm{df}=9, \mathrm{sig}=0.001\right)$. All independent variables within the order response model indicated a $62 \%$ variance for the likelihood or probability of travel evading by the travellers in India due to COVID-19 pandemic (Table 6). ORM was used to answer the research questions by revealing the relationships between the constructs.

With regard to $R Q 1$, the ORM suggested a positive association between perceived risk of travel and travel evading intentions ( $\beta=1.520, p=0.001$ ). Thus, it can be deduced that the Indian travellers who perceived a higher level of travel risks from COVID-19 were more likely to evade travel within and outside India. Results of ORM related to RQ2 found positive momentous association between the perceived severity and probability of travel evading ( $\beta=0.332, p=0.001)$ due to COVID-19 amongst respondents. Thus, the travellers who either perceived higher levels of contraction by COVID- 19 or felt that they might transmit the disease to their friends and family member were found to be probable to evade travel. For $R Q 3$, the ORM established a negative association between personal efficacy and the probability of travel evading ( $\beta=-0.323, p=0.001)$. Therefore, the individuals having low personal efficacy concerning COVID-19 were more probable to evade travel.

As far as $R Q 4$ is concerned, the ORM established a significant positive association between the perceived vulnerability and travel evading intentions of travellers due to COVID-19 ( $\beta=$ $0.653, p=0.001$ ). Therefore, the individuals who perceived higher levels of vulnerability due to COVID-19, were found to show more travel evading tendencies. On RQ5, the model revealed a positive momentous association between subjective acquaintance and the probability of travel evading ( $\beta=0.304, p=0.001$ ) which confirms that travellers who

\section{Table 6 Parameter estimates of the ordered response model}

\begin{tabular}{lcc} 
Study constructs of health belief model & Parameter estimates $(\beta)$ & Level of significance (p-value) \\
\hline Perceived risk of travel & 1.520 & 0.001 \\
Perceived severity & 0.332 & 0.001 \\
Personal efficacy & -0.323 & 0.001 \\
Perceived vulnerability & 0.653 & 0.001 \\
Subjective acquaintance & 0.304 & 0.001 \\
Male (ref: female) & 0.259 & 0.002 \\
Age & -0.023 & 0.001 \\
International travel & 0.004 & 0.329 \\
Travel evading limits: evade travel =1 & 5.124 & 0.001 \\
Evade travel $=2$ & 5.956 & 0.001 \\
Evade travel $=3$ & 7.233 & 0.001 \\
Evade travel $=4$ & 8.112 & 0.001
\end{tabular}

Notes: Pseudo $R^{2}$ Negelkerke $=0.529$, Sig $<0.05 ;-2$ Log likelihood with convergence rate of $3540.444\left(\chi^{2}=1121.234, \mathrm{df}=9\right.$, sig $\left.=0.001\right)$ 
exhibit higher grades of subjective acquaintance are more likely to evade travel due to COVID-19.

The findings related to $R Q 6$, which were based upon the association between the sociodemographic profile of Indian travellers and their travel evading intentions, revealed interesting findings. ORM established a negative connection between a traveller's age and their probability to evade travel $(\beta=-0.023, p=0.001)$, though the tendency of travel evading was found to be much stronger in the age brackets above 45 years as compared to the other age groups due to COVID-19. A significant positive association was also found between the travel evading intentions and the gender $(\beta=0.259, p=0.002)$ of respondents, with males being more probable to evade travel due to COVID-19. As the majority of respondents have not travelled abroad in the past 12 months, no momentous association was established between the frequency of international travel and the likelihood to evade travel ( $\beta=0.004, p=0.329)$.

\section{Conclusion and discussions}

This study addressed circumstances and factors associated with the travel intentions of Indian tourists, specifically related to travel avoidance due to COVID-19. Factors influencing whether the Indian tourists avoided travelling abroad were explored, and the relationship between perceived risk of travelling and the probability of travel evading in India due to COVID-19 were identified.

The results of this study were different from similar studies which indicated that pandemics have a minimal effect on travel (Maxouris, 2020). Moreover, respondents' perceptions of travel evading were found to be much stronger in this study as compared to the previous study (Cahyanto et al., 2016) on Ebola outbreak in the USA in which respondents indicated that they would not avoid travel due to Ebola.

The findings were found to be consistent with the previous literature using the HBM except for a few parameters. For example, the significant positive association established between the perceived risk of travelling and travel evading intentions was found to be consistent with the earlier findings of Bish and Michie (2010). This confirms that the travellers who perceived higher risk levels have a greater tendency towards travel evading in India. Also, the findings on the negative relationship of personal efficacy with travel evading intentions were found to be consistent with the earlier findings of Lu et al. (2020). This suggests that the Indian tourists who have low personal efficacy are likely to evade travel due to COVID19. Moreover, our results on the positive association between perceived vulnerability about COVID-19 and travel evading intentions were found to be consistent with the previous findings of Brewer and Fazekas (2007). This also confirms that tourists who have high grades of vulnerability towards the contraction with COVID-19 are likely to evade travel.

This study's findings related to the relationship between gender and travel evading were found to be inconsistent with the earlier studies that found travel evading to be stronger in females during a health crisis (Cahyanto et al., 2016). Moreover, travel evading intentions were found to be much stronger in the age groups of 45 years and above which is inconsistent with earlier research conducted by Carpenter (2010) that found such travel evading to be higher for the age groups below 35 years. Travel evading intentions of the Indian tourists studied were similar for both domestic and international travel which contrasts with earlier findings of Cahyanto et al. (2016) in which only international travellers intended to evade travel, and domestic travellers continued to travel.

This study revealed some findings that have implications for stakeholders and the industry to re-emerge from this global pandemic. The factors explored in this study which affect the travel evading intentions of the Indian travellers may be considered by the stakeholders in tourism and hospitality businesses to devise strategies to reduce the travel-associated risks and increase the benefits. This may be done by placing emphasis on providing medical 
and travel insurance to reduce risk and enhance travel safety. As the majority of the travellers in this study cited the risk of COVID-19 contraction as the reason for not travelling, stakeholders should devise consumer training and awareness initiatives to reduce their perceived severity intentions linked with COVID-19 by taking adequate preventive measures. This might be done through online platforms or by COVID-19 information through travel tickets, boarding passes, information centres in airports, hotel rooms, etc.

The findings also have implications for governments that would be well served to implement measures to build confidence amongst tourists and the industry. As the perceived high risk of travel is bound to remain for some time even after the outbreak, initiatives like the launch of Fit for Travel and Arogya Setu mobile applications should be promoted. Such measures provide travellers with real-time updates about nearby active COVID-19 cases and allow them to track their own perceptiveness towards the disease. Financial assistance through subsidised government loans for small- and medium-sized hotel establishments may also help them to re-establish and rebuild their businesses. Local governments should also promote physical distancing by maintaining strict control or restricting/limiting the tourist entries at famous monuments, museums and other prominent tourist destinations to foster confidence amongst travellers and hospitality and tourism service providers in the prominent tourism cities. The results of this study emphasising on risk perception and efficacy beliefs towards COVID-19 can also assist in motivating the public to engage in preventive measures by using precautionary messages.

This study suggests some theoretical implications and points to new directions for future research. These directions can reinforce findings from the current study on how travel evading behaviours of tourists are influenced or may assist in developing novel parameters and offer improved results. It may also help in developing future studies on how potential travellers may negotiate their intention to travel with their perceived risks in the event of a pandemic. The findings of this study can be used as a baseline for larger in-depth studies to identify factors significantly associated with these problems. It can also be instructive for strategies potential travellers may use to increase their personal efficacy towards COVID19. The study also has implications regarding the effects of cognitive factors of HBM. Moreover, the study findings will also assist researchers and scholars to identify and formulate more significant factors (apart from the HBM constructs) that may have an impact on the travel evading intentions of the tourists (perhaps from the perspective of tourists that are non-Indian).

\section{Implications for future tourism}

Opening up the tourism sector is going to be more difficult than shutting it down, and this will require a balanced and measured approach. While the delay in re-opening and continued uncertainty creates further challenges for the tourism sector, moving too quickly risks dampening consumer confidence in getting the sector up and running in the longer run. As discussed in this study, this crisis is expected to have a permanent impact on consumer travel behaviour, accelerating the move to online activities, with a greater emphasis on hygiene and healthy living and increased use of cashless and contactless payment methods. It is evident that novel measure by industry stakeholders will be required to restore travellers' and employees' confidence. The recent trends of travellers' demographics in China (after the lockdown) were found to be consistent with our study findings and show that travellers' demographics have shifted to younger and non-family travellers (McKinsey and Company, 2020). Moreover, as the travel evading intentions were found to be stronger among female consumers, appropriate measures must be taken by the stakeholders to boost their confidence by providing stringent hygiene, safety and prevention measures both at the destination and during travel (Dimitri and Szilvia, 2020). These measures may include ensuring physical distancing and proper sanitation measures, 
use of aggressive price promotion and engaging tourists through social media targeting the younger consumer segment.

Due to restrictions on international travel, the demand for business travel, luxury hotels and MICE tourism has declined, and this will provide an opportunity for the emergence and development of other domestic tourism segments (Niewiadomski, 2020). As this study found the travel evading intentions of the respondents to be stronger for international travel after the COVID-19 outbreak, DMO's and other tourism stakeholders should take appropriate measures to promote domestic travel, especially in the major tourism bound cities to rejuvenate the industry. Domestic tourism offers the primary opportunity for driving recovery and supporting the tourism sector in India. Domestic tourism flows have been heavily affected by restrictions on the movement of people but are expected to recover more quickly once containment measures are lifted. Nonetheless, it is unlikely that domestic tourism could completely compensate for the decline of international tourism flows, particularly in destinations heavily dependent on international markets. As a short-term measure, local governments and DMOs should try to revive the tourism sector by helping smaller- and middle-sized businesses that have been greatly affected by COVID-19, while promoting destinations that are less affected by the virus. However, as a long-term measure, a comprehensive strategy must be developed to deal with the pandemic and other related issues while supporting the local authorities and enterprises to develop their tourism potential.

\section{Limitations}

As this study attempted to identify the factors which affect tourists' travel evading intentions in India, it has a few limitations, and as such, we offer some suggestions. First, as the online survey for this study was conducted at the time when the COVID-19 outbreak was at its peak (March 2020), and it was highly covered by the media, tourists' travel evading perceptions might be affected by it. Therefore, the generalisation of results might become a significant limitation. Second, as the data collection was done through an online survey; it relied solely upon the self-reported information with its intrinsic bias (though the bias was removed using Harman's single factor test). Further studies might look to do similar surveys using a more appropriate sampling technique. Third, due to the complicated nature of the problem, further studies might be needed to completely comprehend the intricacy of attitudes and perceptions towards infectious illnesses such as COVID-19.

Finally, due to the limitation of going in the field to collect the responses (due to the lockdown), the online survey was conducted which resulted in a majority of the sample being skewed towards highly educated groups (i.e. graduates, post-graduates and doctorates). However, considering the current developments on COVID-19 and travel, it is quite evident that due to COVID-19, travel will become a luxury again (as the industry will spend more on their safety, cleanliness and sanitation efforts). Therefore, highly educated individuals will be a valuable group to study post-COVID-19 pandemic. However, further studies may consider less educated groups as well, as they constitute a significant tourist market in India.

\section{References}

Adams, J. and Scott, J. (2000), "Predicting medication adherence in severe mental disorders", Acta Psychiatrica Scandinavica, Vol. 101 No. 2, pp. 119-124.

Aksoy, C.G., Ganslmeier, M. and Poutvaara, P. (2020), "Public attention and policy responses to COVID-19 pandemic", available at SSRN 3638340.

Anagnostopoulos, F., Dimitrakaki, C., Niakas, D. and Tountas, Y. (2013), "Validity and reliability assessment of health belief scales for mammography screening in Greek asymptomatic women", Psycho-Oncology, Vol. 22 No. 8, pp. 1912-1917. 
Arana, J. and Leon, C. (2008), "The impact of terrorism on tourist demand", Annals of Tourism Research, Vol. 35 No. 2, pp. 299-315, doi: 10.1016/j.annals.2007.08.003.

Baker, T. (2020), "Chinese hotels seeing steep declines from coronavirus", available at: http:// hotelnewsnow.com/Articles/300132/Chinese-hotels-seeing-steep-declines-fromcoronavirus (accessed 3 April 2020).

Bandura, A. (1977), "Self-efficacy: towards a unifying theory of behavioural change", Psychological Review, Vol. 84 No. 2, pp. 191-215.

Bergmann, K. (2020), "COVID-19: what the world can learn from Asia", Defence Review Asia, Vol. 14 No. 2, p. 4.

Binnicker, M. (2020), "Emergence of a novel coronavirus disease (COVID-19) and the importance of diagnostic testing: why partnership between clinical laboratories, public health agencies, and industry is essential to control the outbreak", Clinical Chemistry, Vol. 66 No. 5, pp. 1-3.

Bish, A. and Michie, S. (2010), "Demographic and attitudinal determinants of protective behaviours during a pandemic: a review", British Journal of Health Psychology, Vol. 15 No. 4, pp. 797-824.

Bo, H.X., Li, W., Yang, Y., Wang, Y., Zhang, Q., Cheung, T., Wu, X. and Xiang, Y.T. (2020), "Post traumatic stress symptoms and attitude toward crisis mental health services among clinically stable patients with COVID-19 in China", Psychological Medicine, pp. 1-2, available at: https://doi.org/10.1017/ S0033291720000999

Brewer, N.T. and Fazekas, K.I. (2007), "Predictors of HPV vaccine acceptability: a theory-informed, systematic review", Preventive Medicine, Vol. 45 Nos 2/3, pp. 107-114.

Brewer, N.T. and Hallman, W.K. (2006), "Subjective and objective risk as predictors of influenza vaccination during the vaccine shortage of 2004-2005", Clinical Infectious Diseases, Vol. 43 No. 11, pp. 1379-1386.

Buckley (2020), "Chinese doctor, silenced after warning of outbreak, dies from coronavirus", New York Times, available at: www.nytimes.com/2020/02/06/world/asia/Li-Wenliangcoronavirus.html (accessed 27 March 2020)

Bureau of Immigration (2020), "Advisory: travel and visa restrictions related to Covid-19", available at: https://boi.gov.in/content/advisory-travel-and-visa-restrictions-related-covid-19-0 (accessed 3 April 2020).

Cahyanto, I., Wiblishauser, M., Pennington-Gray, L. and Schroeder, A. (2016), "The dynamics of travel avoidance: the case of Ebola in the US", Tourism Management Perspectives, Vol. 20 No. 2016, pp. 195-203.

Carpenter, C.J. (2010), "A meta-analysis of the effectiveness of the HBM variables in predicting behaviour", Health Communication, Vol. 25 No. 8, pp. 661-669.

Carr, N. (2001), "An exploratory study of gendered differences in young tourists' perception of danger within London", Tourism Management, Vol. 22 No. 5, pp. 565-570.

Chapman, G.B. and Coups, E.J. (1999), "Predictors of influenza vaccine acceptance among healthy adults", Preventive Medicine, Vol. 29 No. 4, pp. 249-262.

Crompton, J. (1992), "Structure of vacation destination choice sets", Annals of Tourism Research, Vol. 19 No. 3, pp. 424-434.

De Coninck, D., d' Haenens, L. and Matthijs, K. (2020), "Perceived vulnerability to disease and attitudes towards public health measures: Covid-19 in Flanders, Belgium", Personality and Individual Differences, Vol. 166 No. 1, doi: 10.1016/j.paid.2020.110220.

Dillman, D., Smyth, J. and Christian, L. (2009), Internet, Mail, and Mixed-Mode Surveys: The Tailored Design Method, Wiley, New York, NY.

Dimitri, I. and Szilvia, G. (2020), "The COVID-19 crisis as an opportunity for escaping the unsustainable global tourism path", Tourism Geographies, doi: 10.1080/14616688.2020.1763445.

Englander, D. (1991), "What you need to know to fly safely now", Money, Vol. 29 No. 3, p. 156.

Godin, M. (2020), "Why is Italy's coronavirus outbreak is so bad?", Time- e magazine, available at: https:// time.com/5799586/italy-coronavirus-outbreak/ (accessed 4 April 2020).

Gorbalenya, A.E., Baker, S.C., Babic, R.S., de Groot, R.J., Drosten, C. and Gulyaeva, A.A. (2020), "Severe acute respiratory syndrome related coronavirus: the species and its viruses - a statement of the coronavirus study group", BioRxiv-2020, doi: 10.1101/2020.02.07.937862. 
Gupta, V. and Sajnani, M. (2019), "Risk and benefit perceptions related to wine consumption and how it influences consumers' attitude and behavioural intentions in India", British Food Journal, Vol. 122 No. 8, doi: 10.1108/BFJ-06-2019-0464.

Hanson, J.A. and Benedict, J.A. (2002), "Use of the HBM to examine older adults' food handling behaviours", Journal of Nutrition Education and Behavior, Vol. 34 No. 1, pp. S25-S30.

Hindustan Times (2020), "Covid-19: a plan for tourism to survive, revive, thrive", available at: www. hindustantimes.com/analysis/covid-a-plan-for-tourism-to-survive-revive-thrive/story-07EpP7FreQtXDKSs 7zxkuK.html (accessed 2 October 2020).

Hounton, S.H., Carabin, H. and Henderson, N.J. (2005), "Towards an understanding of barriers to condom use in rural Benin using the HBM: a cross sectional survey", BMC Public Health, Vol. 5 No. 1, p. 8.

Huang, X., Dai, S. and Xu, H. (2020), "Predicting tourists' health risk preventative behaviour and travelling satisfaction in Tibet: combining the theory of planned behaviour and health belief model", Tourism Management Perspectives, Vol. 33, doi: 10.1016/j.tmp.2019.100589.

Hui, D.S., Azhar E, I., Madani, T.A., Ntoumi, F., Kock, R. and Dar, O. (2020), "The continuing 2019-nCoV epidemic threat of novel coronaviruses to global health - the latest 2019 novel coronavirus outbreak in Wuhan, China", International Journal of Infectious Diseases, Vol. 91, pp. 264-266.

Janz, N.K. and Becker, M.H. (1984), "The HBM: a decade later", Health Education Quarterly, Vol. 11 No. 1, pp. 1-47.

Jose, R., Narendran, M., Bindu, A., Beevi, N., Manju, L. and Benny, P.V. (2020), "Public perception and preparedness for the pandemic COVID 19: a health belief model approach", Clinical Epidemiology and Global Health, Vol. 9, doi: 10.1016/j.cegh.2020.06.009.

Kuo, H.I., Chen, C.C., Tseng, W.C., Ju, L.F. and Huang, B.W. (2008), "Assessing impacts of SARS and avian flu on international tourism demand to Asia", Tourism Management, Vol. 29 No. 5, pp. 917-928.

Lee, M. and You, M. (2020), "Psychological and behavioral responses in South Korea during the early stages of coronavirus disease 2019 (COVID-19)", International Journal of Environmental Research and Public Health, Vol. 17 No. 9, p. 2977, doi: 10.3390/ijerph17092977.

Lee, C., Son, H., Bendle, L., Kim, M. and Han, H. (2012), "The impact of non-pharmaceutical interventions for 2009 H1N1 influenza on travel intentions: a model of goal-directed behaviour", Tourism Management, Vol. 33 No. 1, pp. 89-99.

Leggat, P.A., Brown, L.H., Aitken, P. and Speare, R. (2010), "Level of concern and precaution taking among Australians regarding travel during pandemic (H1N1) 2009: results from the 2009 Queensland social survey", Journal of Travel Medicine, Vol. 17 No. 5, pp. 291-295.

Lepp, A. and Gibson, H. (2003), "Tourist roles, perceived risk and international tourism", Annals of Tourism Research, Vol. 30 No. 3, pp. 606-624

Lu, R., Zhao, X., Li, J., Niu, P.Y.B. and Wu, H. (2020), "Genomic characterisation and epidemiology of 2019 novel coronavirus: implications for virus origins and receptor binding", Lancet (London, England), Vol. 395 No. 10224 , pp. 565-574.

McKinsey \& Company (2020), "The way back: what the world can learn from China's travel restart after COVID-19", available at: www.oecd.org/coronavirus/policy-responses/tourism-policy-responses-to-thecoronavirus-covid-19-6466aa20/ (accessed 27 July 2020).

Maser, B. and Weiermair, K. (1998), "Travel decision-making: from the vintage point of perceived risk and information preferences", Journal of Travel \& Tourism Marketing, Vol. 7 No. 4, pp. 107-121.

Mavondo, F.T. and Reisinger, Y. (2005), "Travel anxiety and intentions to travel internationally: implications of travel risk perception", Journal of Travel Research, Vol. 43 No. 3, pp. 212-225.

Maxouris, C. (2020), "US enforces coronavirus travel restrictions: China says it's an overreaction", CNN, CNN travel, available at: www.cnn.com/travel/article/coronavirus-us-travel-restrictions-monday/index. html (accessed 3 April 2020).

Mitchell, V.W. and Vassos, V. (1997), "Perceived risk and risk reduction in holiday purchases: a crosscultural and gender analysis", Journal of Euromarketing, Vol. 6 No. 3, pp. 47-80.

Nicholls, H. (2006), "Pandemic influenza: the inside story", PLoS Biology, Vol. 4 No. 2, p. e50, doi: 10.1371/journal.pbio.0040050. 
Niewiadomski, P. (2020), "COVID-19: from temporary de-globalisation to a re-discovery of tourism?", Tourism Geographies, Vol. 22 No. 3, doi: 10.1080/14616688.2020.1757749.

Page, S., Yeoman, I., Munro, C., Connell, J. and Walker, L. (2006), "A case study of best practice - visit Scotland's prepared response to an influenza pandemic", Tourism Management, Vol. 27 No. 3, pp. 361-393.

Pine, R. and McKercher, B. (2004), "The impact of SARS on Hong Kong's tourism industry", International Journal of Contemporary Hospitality Management, Vol. 16 No. 2, pp. 139-143.

Riley, C. (2020), "This is a crisis.' airlines face $\$ 113$ billion hit from the coronavirus", available at: https:// edition.cnn.com/2020/03/05/business/airlines-coronavirus-iata-travel/index.html (accessed 2 April 2020).

Roehl, W. and Fesenmaier, D. (1992), "Risk perceptions and pleasure travel: an exploratory analysis", Journal of Travel Research, Vol. 30 No. 4, pp. 17-26.

Rosenstock, I.M., Strecher, V.J. and Becker, M.H. (1988), "Social learning theory and the HBM", Health Education \& Behaviour, Vol. 15 No. 2, pp. 175-183.

Schiffman, L. and Kanuk, L. (1991), Consumer Behaviour, Prentice Hall, Englewood Cliffs, NJ.

Sharifirad, G., Entezari, M.H., Kamran, A. and Azadbakht, L. (2009), "The effectiveness of nutritional education on the knowledge of diabetic patients using the HBM", Journal of Research in Medical Sciences: The Official Journal of Isfahan University of Medical Sciences, Vol. 14 No. 1, p. 1.

Statista (2020), "Opinion on government-implemented travel restrictions on foreign travellers due to the coronavirus COVID-19 in India in march 2020", available at: www.statista.com/statistics/1103892/indiapublic-opinion-on-travel-restrictions-coronavirus/\#statisticContainer (accessed 31 March 2020).

The Economic Times (2020), "Coronavirus outbreak will setback India's growth recovery", available at: https://economictimes.indiatimes.com/news/economy/policy/outbreak-will-set-back-indias-growth-recovery/ articleshow/74663633.cms?from=mdr (accessed 20 March 2020).

Tsaur, S.-H., G-H. Tzeng and Wang, K.-C. (1997), "Evaluating tourist risks from fuzzy perspectives", Annals of Tourism Research, Vol. 24 No. 4, pp. 796-812.

UNWTO (2020), "Impact assessment of the COVID-19 outbreak on international tourism", available at: www.unwto.org/impact-assessment-of-the-covid-19-outbreak-on-international-tourism (accessed 28 March 2020).

Worldometers (2020), "Covid-19- Pandemic", available at: www.worldometers.info/coronavirus/ \#countries (accessed 26 July 2020).

Yang, Y. and Chen, X. (2020), "Coronavirus pandemic and tourism: dynamic stochastic general equilibrium modelling of infectious disease outbreak", Annals of Tourism Research, Vol. 83.

Yuda, M. and Tani, S. (2020), "Coronavirus hits Thailand hardest in tourism-reliant SE Asia: hotel and airline stocks sink as China's travel ban kicks in", available at: https://asia.nikkei.com/Spotlight/ Coronavirus-outbreak/Coronavirus-hits-Thailand-hardest-in-tourism-reliant-SE-Asia (accessed 27 March 2020).

Zhu, N., Zheng, D., Wang, W., Xingwang, L., Yang, B. and Song, J. (2019), "A novel coronavirus from patients with pneumonia in China, 2019", New England Journal of Medicine, Vol. 382 No. 8, pp. 727-733.

\section{Further reading}

Folayan, M. and Brown, B. (2015), "Ebola and the limited effectiveness of travel restrictions", Disaster Medicine and Public Health Preparedness, Vol. 1 No. 1.

Leggat, P.A. and Klein, M. (2001), "Personal safety advice for travellers abroad", Journal of Travel Medicine, Vol. 8 No. 1, pp. 46-51.

Morison, A. (2005), National Quirks Add Cues to Grim Game of Chance, South China Morning Post, (accessed 3 January 2020).

The Indian Express (2020), "Timely lockdown gave India an edge in war against coronavirus", available at: https://indianexpress.com/article/opinion/columns/india-coronvirus-lockdown-covid-19-spread-vacineicmr-testing-vinod-paul-6526381/ (accessed 29 July 2020). 


\section{About the authors}

Dr Vikas Gupta is an alumnus of Amity University, Uttar Pradesh, India, and holds a PhD in hospitality. He has also done his master's degree in Tourism Management and Bachelor degree in Hospitality and Hotel Administration. He also holds a Diploma in Training and Development from Indian Society for Training and Development. Apart from his academic credentials, he possesses exemplary leadership and training skills, making him a really sought-after professional especially in the fields of Food Production and Culinary Arts. He has rich and extensive experience of teaching for more than 12 years in both India and abroad with renowned names such as Café Coffee Day, Fiji National University, Amity University and Various Central and State IHM's in India. He is presently working with Amity University, Noida, Uttar Pradesh, as an Assistant Professor in the fields of Hospitality. He also has a very good research background with publications in National and International Journals including Emerald SCOPUS indexed journals, i.e. International Journal of Contemporary Hospitality Management, Tourism Review, British Food Journal, Worldwide hospitality and Tourism themes and International Journal of Tourism Cities. His research is also published in form of various national and international conference proceedings. Vikas Gupta is the corresponding author and can be contacted at: vgupta6@amity.edu

Dr Ignatius Cahyanto is an Assistant Professor at University of Louisiana at Lafayette. He has also worked with Black Hills State University in South Dakota, USA, as an Assistant Professor. He has earned the esteemed Coca-Cola/BORSF Endowed Professorship in Hospitality Management. His research interest is centred around crisis management for the tourism industry. He is particularly interested in understanding tourists' behaviour in the event of crises.

Professor Manohar Sajnani, who a celebrated professional with more than 30 years teaching and industry experience, is a Destination Marketing and Tourism Management Expert with specialisation in Information Communication Technologies in Tourism and Hospitality industry. His research area is inter-disciplinary cutting across a number of disciplines including People Management and Tourism Business Laws, creating value for both travel organisations and the end users. He is a Consultant, Scholar, Distinguished Academician and a thought leader in true sense who is known for his passion to bring practical orientation to academics in Tourism and Hospitality across different levels of education. He is researching, lecturing, advising and consulting Tourism and Hospitality organisations and his books and publications are referred to widely by all sections of Tourism and Hospitality industry. He is known for engaging audience during his keynote presentations and deliberations at seminars and conferences globally. As a member of Education \& Training Committee (PATA) as well as Think Tank World Tourism Forum, Lucerne, Switzerland, and he has constructively contributed and his dynamic engagement continues towards the betterment of members of all related communities and stakeholders.

Chetan Shah has last worked with The University of the South Pacific as a Lecturer in Tourism and Hospitality Management and is a Consultant for the Central Himalayan Environmental Association (CHEA), India. His research focusses on alternative tourism, sustainability, over tourism perceptions, experience value, destination marketing, consumer behaviour and satisfaction.

For instructions on how to order reprints of this article, please visit our website: www.emeraldgrouppublishing.com/licensing/reprints.htm

Or contact us for further details: permissions@emeraldinsight.com 